«Ranokršćanski spomenici Zadra u svjetlu novijih istrazivanja»; A. Terry, «Documentary Evidence for the Restoration of the Mosaics at the Eufrasiana»; I. Matejčić, «Biskupija Eufrazijane u Poreču».

Sub-secções:

$1^{a}$ : Split-Salona 1894, o Congresso fundador dos Congressos internacionais de arqueologia cristã e G. B. de Rossi, fundador da Arqueologia Cristã:

Sobre a época de Justiniano e os séculos VI e VII:

$2^{a}$ : Europa do Sudeste: Croácia (Dalmácia central e meridional); Bósnia-Herzegovina, Albânia, Grécia);

$3^{a}$ : Urbanismo, fortificações e espaços litúrgicos;

$4^{a}$ : Igrejas urbanas e residências episcopais;

$5^{a}$ : História, generalidades;

$6^{a}$ : Igrejas rurais, espaços litúrgicos, mosteiros e cemitérios;

$7^{a}$ : Escultura, pintura e mosaicos;

$8^{a}$ : Artes menores e numismática;

$9^{a}$ : Epigrafia e onomástica.

Para além das diversas sessões científicas, o Congresso englobou actos de índole social, cultural e religioso em reuniōes de fins de tarde e de início de noite. Destaque-se por exemplo a exposição "Artes minores Salonae Christianae» que ficou aberta durante todo o Congresso no Museu de Arqueologia de Split; o concerto na Basílica Eufrasiana pela Orquestra de Câmara da Radio Televisão Croata; a solene celebração na Catedral de Split presidida pelo cardeal da Croácia ou as visitas do Palácio de Diocleciano e dos palácios medievais de Split, da Catedral romana e da cidade medieval de Trogir, da Igreja paleocristã de Gata e dos monumentos paleocristãos e alto-medievais do bispado de Poreć. As actividades culturais paralelas ao Congresso possibilitaram o diálogo da comunidade científica com a comunidade local.

As Actas do Congresso a publicar pelo Pontifício Instituto de Arqueologia Cristã de Roma e pelo Museu Arqueológico de Split constituirão certamente a melhor referência para avaliar a qualidade deste Congresso, que não pretendeu um mero regresso ao passado da arqueologia cristã mas um aprofundamento das especificidades deste ramo do saber, abrindo novas pistas para a realização de estudos interdisciplinares em áreas ainda pouco trabalhadas da Antiguidade Tardia.

Ana Maria Jorge

\title{
$30{ }^{\text {th }}$ INTERNATIONAL CONGRESS ON MEDIEVAL STUDIES
}

Nos dias 4 a 7 de Maio de 1995, realizou-se em Kalamazoo (Michigan - E.U.A.) o 30. ${ }^{\text {th }}$ International Congress on Medieval Studies. O Congresso é organizado desde há três décadas pelo Instituto de Estudos Medievais da Western Michigan Uni- 
versity, reunindo medievalistas de todo o mundo. Nesta sessão estiveram presentes aproximadamente 3000 investigadores, distribuídos por 447 sessões.

Em termos de áreas de trabalho a reunião privilegiou os estudos sermonísti$\cos$, homiléticos e relativos a ordens religiosas. Quer nestas temáticas quer noutras, de leque muito variado - como sejam a historiografia, a linguística, e as ideologias -, os estudos ibéricos tiveram uma significativa representação.

A presença portuguesa foi assegurada pelas subscritoras destas linhas numa sessão coordenada pelo Prof. Alberto Ferreiro (Seattle Pacific University). As comunicações apresentadas procuraram fazer o ponto da situação da historiografia moderna portuguesa em diferentes vertentes:

- Ana Maria Jorge (CEHR) - «Religious History in Galicia and Lusitania in Late Antiquity and the Early Middle Ages: Current historiography and future research».

- Maria João Branco (Univ. Aberta - Lisboa) - «Kings, Bishops and Nobles: The labyrinths of Power in Medieval Portugal in the XI-XIV centuries. A state of the question».

- Maria de Lurdes Rosa (CEHR) - «Religiosity and religious culture of the nobility in the Late Middle Ages».

Em complemento ao Congresso realizou-se uma ampla feira de livros de temática medieval, onde estiveram representadas todas as editoras universitárias especializadas dos Estados Unidos e área anglófona, bem como as de um significativo número de países europeus.

Ana Maria Jorge

Maria João Branco

Maria de Lurdes Rosa

\section{ENCONTROS DE HISTÓRIA DOMINICANOS (1994-1995): D. DOMINGOS FRUTUOSO E O SEU TEMPO}

Dentro da proposta de fazer do novo convento de S. Domingos em Lisboa «um espaço aberto para o exterior", um centro cultural, os responsáveis organizaram como primeira actividade uma série de Encontros de História sob o tema D. Domingos Frutuoso e o seu tempo. Previstos sete Encontros entre Outubro de 1994 e Maio de 1995, realizaram-se seis: o último-A Restauração: D. Domingos Frutuoso - não ocorreu por impedimento do conferencista.

Tomando como referência a figura do grande bispo dominicano, que entrou para a ordem já depois de ordenado sacerdote secular, o fio condutor dos Encontros foi a questão da relação ordens religiosas e Estado português nos séculos XIX e XX.

O primeiro Encontro versou sobre a Igreja e Sociedade portuguesa do liberalismo à República sob responsabilidade do Pe. Doutor Manuel Clemente. Segundo o autor, a introdução do liberalismo em Portugal significou um novo relaciona- 